\title{
Identification of Priority Areas for Conservation of Two Endangered Parapatric Species of Red-bellied Toads Using Ecological Niche Models and Hotspot Analysis
}

\author{
Jorge Bernardo-Silva ${ }^{1 *}$, Claiton Martins-Ferreira ${ }^{2}$, \\ Raul Maneyro ${ }^{3}$ \& Thales Renato Ochotorena de Freitas ${ }^{2}$
}

\author{
${ }^{1}$ Programa de Pós-graduação em Ecologia, Instituto de Biociências, Universidade Federal do Rio Grande do Sul - UFRGS, \\ Porto Alegre, RS, Brasil \\ 2 Departamento de Genética, Instituto de Biociências, Universidade Federal do Rio Grande do Sul - UFRGS, \\ Porto Alegre, RS, Brasil \\ ${ }^{3}$ Laboratorio de Sistemática e Historia Natural de Vertebrados, Facultad de Ciencias, Universidad de La República \\ Uruguay - UDELAR, Montevideo, Uruguay
}

\begin{abstract}
The red-bellied toads Melanophryniscus dorsalis and M. montevidensis are listed as vulnerable on the IUCN list. Uruguayan populations of $M$. montevidensis are no longer found near the southern limit of its distribution, and information on the ecology and distribution of both species is still needed. We are proposing consensus models and hotspot analysis to identify priority conservation areas for these toads. Here, we present a consensus model based on three algorithms that use presence-only data (BIOCLIM, GARP and Maximum Entropy). Through consensus models, we used a new OpenModeller implementation called "hotspot", which identifies areas of high environmental suitability. Our results indicated areas of high environmental suitability for both species. Fieldwork validation also indicated their absence from some high-suitability areas identified by the consensus and hotspot models. Five hotspot areas of great interest to preserve both species are proposed
\end{abstract}

Key words: BIOCLIM, Consensus Model, Conservation Biology, GARP, Maximum Entropy.

\section{Introduction}

Amphibians are one of the groups of organisms with the highest conservation concern worldwide, because of their continuous and steady decline, mainly from climate change, pollution, infectious diseases, and UV radiation (Crawford et al. 2010) as well as habitat loss and competition from invasive alien species (Stuart et al. 2004). Although a variety of general causes of decline are known, it is necessary to determine the reasons for specific declines of each taxon so that remedial actions can be taken. In addition, the identification of an endangered species can result in conservation efforts not only for the specific taxon, but also for the habitat, or part of it, of the key species. However, any effort at conservation should be based on reliable and detailed studies on occurrence and habitat occupation.

The use of ecological niche models (ENM) to infer species distributions has been growing steadily (Franklin 2009),

*Send correspondence to: Jorge Bernardo-Silva

Programa de Pós-graduação em Ecologia, Instituto de Biociências, Universidade Federal do Rio Grande do Sul UFRGS, Av. Bento Gonçalves, 9500, Porto Alegre, RS, Brasil E-mail: bernardo.silva@ufrgs.br; bernardo.silvaj@gmail.com although different patterns of environmental suitability may be found depending on the algorithms used. Thus, choosing the most appropriate model and algorithms is still a challenge for researchers (Araújo \& New 2007). Besides, based on the features intrinsic to each algorithm, standard protocols to identify areas of potential occurrence are needed (Rodríguez-Soto et al. 2011). In particular cases of restricted distribution or sparse populations of rare or endangered species, using ENM may be necessary to identify a set of areas for protection (De Siqueira et al. 2009).

The red-bellied toads Melanophryniscus dorsalis (Mertens 1933) and M. montevidensis (Phillipi 1902) are small anurans inhabit southern Uruguay and the Brazilian states of Rio Grande do Sul and Santa Catarina and are cited as vulnerable in the Red List of the International Union for Conservation of Nature (IUCN 2011; Kwet et al. 2005; Núñez et al. 2004) see supplementary material S1. Melanophryniscus dorsalis is also listed as vulnerable in the Red List of Threatened Species of Rio Grande do Sul (Garcia \& Vinciprova 2003) and in the Red Book of Brazilian Endangered Fauna (Haddad 2008). In 2011, the "National Plan for Conservation of Herpetology 
Fauna from Southern Brazil (PAN)" was published by the Chico Mendes Institute for Biodiversity Conservation (ICMBio) in association with the Brazilian Ministry of the Environment. This PAN was based on identification of priority actions to address threats to populations of endangered species and their environment, with the main goal of developing actions to ensure the preservation of the diverse amphibians and reptiles in southern Brazil. This initiative can be greatly improved with the use of ENM tools to classify areas of high environmental suitability for endangered species, which can be directly applied to reserve design and conservation planning.

Here we applied ENM to predict the potential geographical distributions of $M$. dorsalis and M. montevidensis, providing updated data on their occurrence and proposing new areas to be considered for their management and conservation.

\section{Material and Methods}

\section{Study area}

The study was conducted on the southern coast of Brazil and on the Uruguay coast. The environment consists of sand dunes and relict 'restinga' forests, bounded by the Cabo de Santa Marta in Santa Catarina to the north and Cabo Polonio in Uruguay to the south (Hesp et al. 2009). We mapped the existing protected areas along the species' distributions (Figure 1) according to the SNAP (National
System of Protected Areas) for Uruguay and the Federal Units and environmental protection areas (APAS) of Brazil, as a basis for discussing conservation implications of ENM modeling of the two species.

\section{Preliminary models and occurrence data}

Current knowledge about the distributions of $M$. dorsalis and M. montevidensis is based on historical records from the literature and from the herpetological collection of the Zoology Department of the Federal University of Rio Grande do Sul (UFRGS) and the collection of Vertebrate Zoology, Facultad de Ciencias, Universidad de la República, Uruguay (ZVCB) (see Table S1 in the Additional Supporting Information available at www.abeco. org.br). Distribution estimates may therefore be subject to identification errors, resulting in biased estimations of geographical distributions. To check these historical data, we initially generated a preliminary distribution map using MAXENT (Phillips et al. 2006), which was used to identify areas for 12 field expeditions. Through these field expeditions, we confirmed the historical records and searched for new occurrences in the most suitable areas as determined by the MAXENT model. The coordinates were recorded using a GPS at the exact point of collection or observation (the historical and new records, as well as the parameters of the initial MAXENT models are described in Additional Supporting Information, Tables S1 and S2).

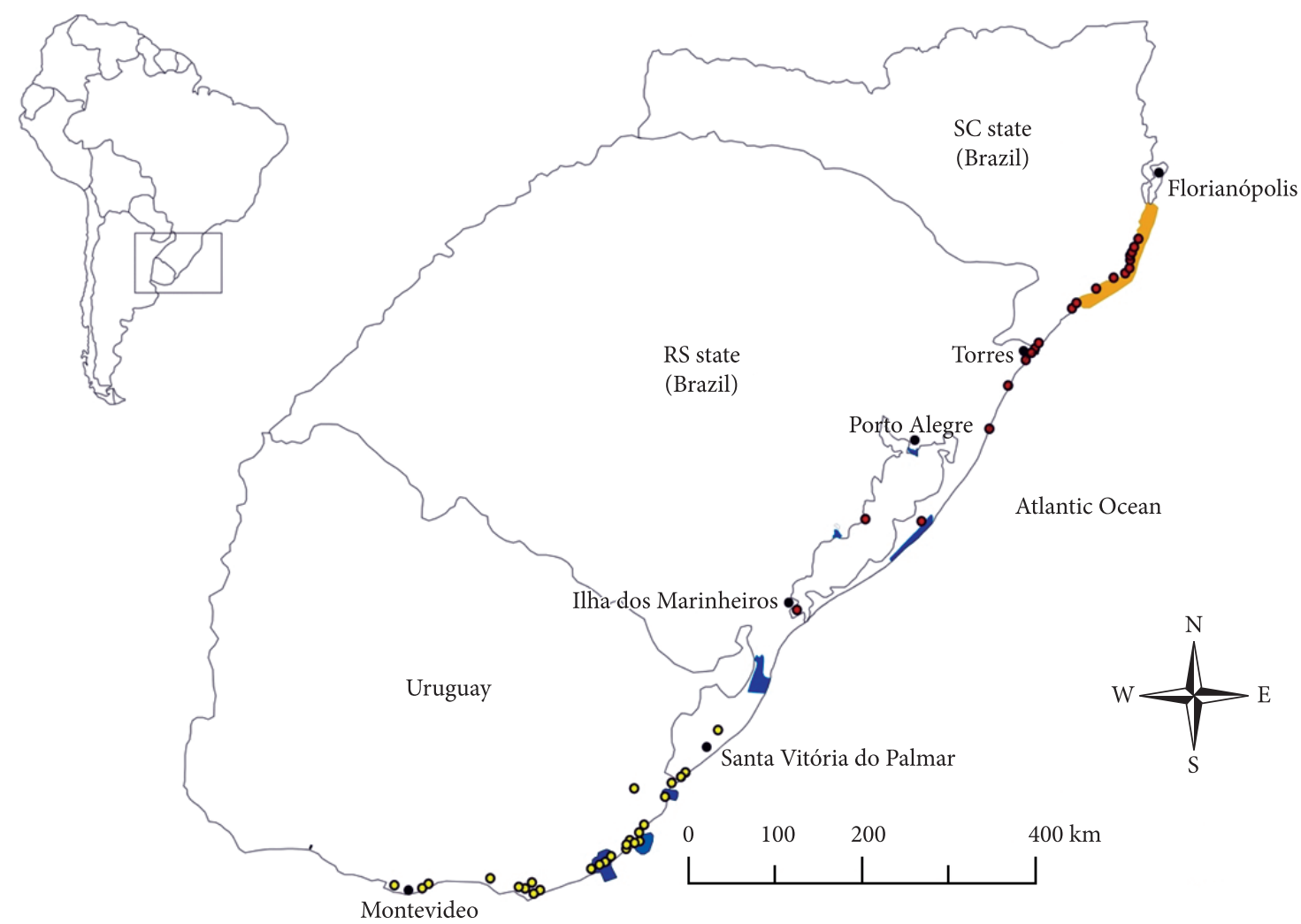

Figure 1. Occurrence records for Melanophryniscus montevidensis (yellow circles) and M. dorsalis (red circles). Blue areas represent the Conservation units of Uruguay (according to SNAP) and the Federal Units of Brazil. Orange areas represent the Brazilian APAS. 
The thorough review of scientific collections and literature allowed us to include records not previously included in the distribution maps from Brazilian red lists, such as points 6 and 8 for $M$. dorsalis, and 19, 20 and 25 for M. montevidensis. Considerable new occurrence data were recorded for this study (Table S1), following the indicated areas in Figure S1. We also included the new record published by Quintela et al. (2007), which extends the known distribution of $M$. dorsalis 285 kilometers to the south and was reconfirmed by this study (point 7) (see Table S1). Field expeditions were conducted to confirm species occurrence in points 6,8 and 10 (M. dorsalis), with a successful rediscovery at point 6 and no success at points 8 and 10. However, for some areas indicated as highly suitable, no records were found (e.g., Florianopolis Island in Santa Catarina; see also Figure 4 and Figure S2).

\section{Environmental data}

We started with 19 Worlclim's bioclimatic variables obtained through interpolated data from derived rainfall and temperature, with a resolution of 2.5 ' arc-minutes (five kilometers) and one variable of altitude (Hijmans et al. 2005), available at http://www.worldclim.org/download. A first model was generated with the historical and new occurrence data to generate a matrix with the values of each climate variable for each occurrence record. We performed a Principal Components Analysis (PCA) on this matrix to identify correlations between variables, selecting the axes that explain $95 \%$ of the correlation structure. From this result we selected variables with the highest absolute coefficient in each axis, allowing to select five bioclimate variables for M. dorsalis (minimum temperature in coldest month, mean temperature in driest quarter, mean temperature in warmest quarter, precipitation in driest month, and altitude) and four variables for M. montevidensis (annual mean temperature, maximum temperature in warmest month, precipitation in wettest quarter, and altitude). To avoid information loss, we included all variables represented in both of the PCAs to generated models for the two species.

\section{Ecological Niche Models}

The models were constructed on OpenModeller version 1.2.0 (Muñoz et al. 2011), available at (http://openmodeller. sourceforge.net/). Five algorithms of presence-only data were used for each species: Mahalanobis Environmental Distances, BIOCLIM, GARP, Maximum Entropy and SVM (Support Vector Machine). We chose this set of methods because they cover different categories of modeling algorithms, such as environmental envelopes, genetic algorithms, and machine learning methods (Franklin 2009; Muñoz et al. 2011). We used the three groups of algorithms to give the best optimization function consensus model, which has clear advantages over the use of a simple model and in principle provides more robust information for conservation plans (Araújo \& New 2007).
From the five outputted models in OpenModeller, two of them (the SVM and Mahalanobis Distances) were discarded because their predictions widely overestimated (although they had acceptable AUC values) the known distributions of both species. These algorithms showed high environmental suitability in all extension of maps, over predicting potential distribution areas including areas of distribution of other species from this genus, such as M. atroluteus (open areas in Brazil and Uruguayan Pampa) and, since our aim was to approximate the realized distribution, and not potential directly by niche, our conservation strategies would be too liberal and more prone to commission errors. All models were validated by calculating the area under the curve (AUC) from a receiver operating characteristic curve (ROC).

For the consensus models, OpenModeller criteria of highest probability for areas that have a higher frequency in the chosen models were used. To identify potential areas for conservation, we used the hotspot function implemented in OpenModeller to obtain a consensus model resulting from common areas of high environmental suitability for both species (see Muñoz et al. 2011). The hotspot function provides a simple result for alpha diversity for each cell, as demonstrated for other rare species of frogs (Giovanelli et al. 2008).

\section{Results}

The consensus map constructed with the algorithms BIOCLIM, GARP and Maximum Entropy (Figures 2 and 3) showed considerable variation in prediction for each species, which is expected due to the algorithm variation. Even so, the high AUC values for both species for all algorithms allowed us to attain high statistical reliability in their predictions (Table S2). The map with the widest distribution area was generated by GARP, whereas BIOCLIM was the most conservative for both species (Figures 2 and 3).

Our results clearly demonstrated that these species have important restrictions in their habitats. Most of the suitable areas are restricted to the southern Brazilian coast for M. dorsalis and to the Uruguayan coast for M. montevidensis. For M. dorsalis, only two records in Brazil were in protected areas: Itapeva and Guarita state parks. These two areas are the only ones with restinga forest with swamps in Rio Grande do Sul. The vast majority of new occurrence records in Santa Catarina are within the APA Baleia Franca (protected area for cetaceans). The consensus map for M. montevidensis showed moderately suitable areas compared to M. dorsalis. The potential distribution of $M$. montevidensis extends from Montevideo in Uruguay to Santa Vitória do Palmar in Brazil (Figure 3).

By integrating the distribution models and the new occurrence records, we identified five areas of high importance using the hotspot function (Figure S2c), three in Brazil and two in Uruguay. Based on specific criteria of environmental suitability of the consensus models and the hotspot function, we found the highest probability for alpha diversity in these areas (Figure 4). 

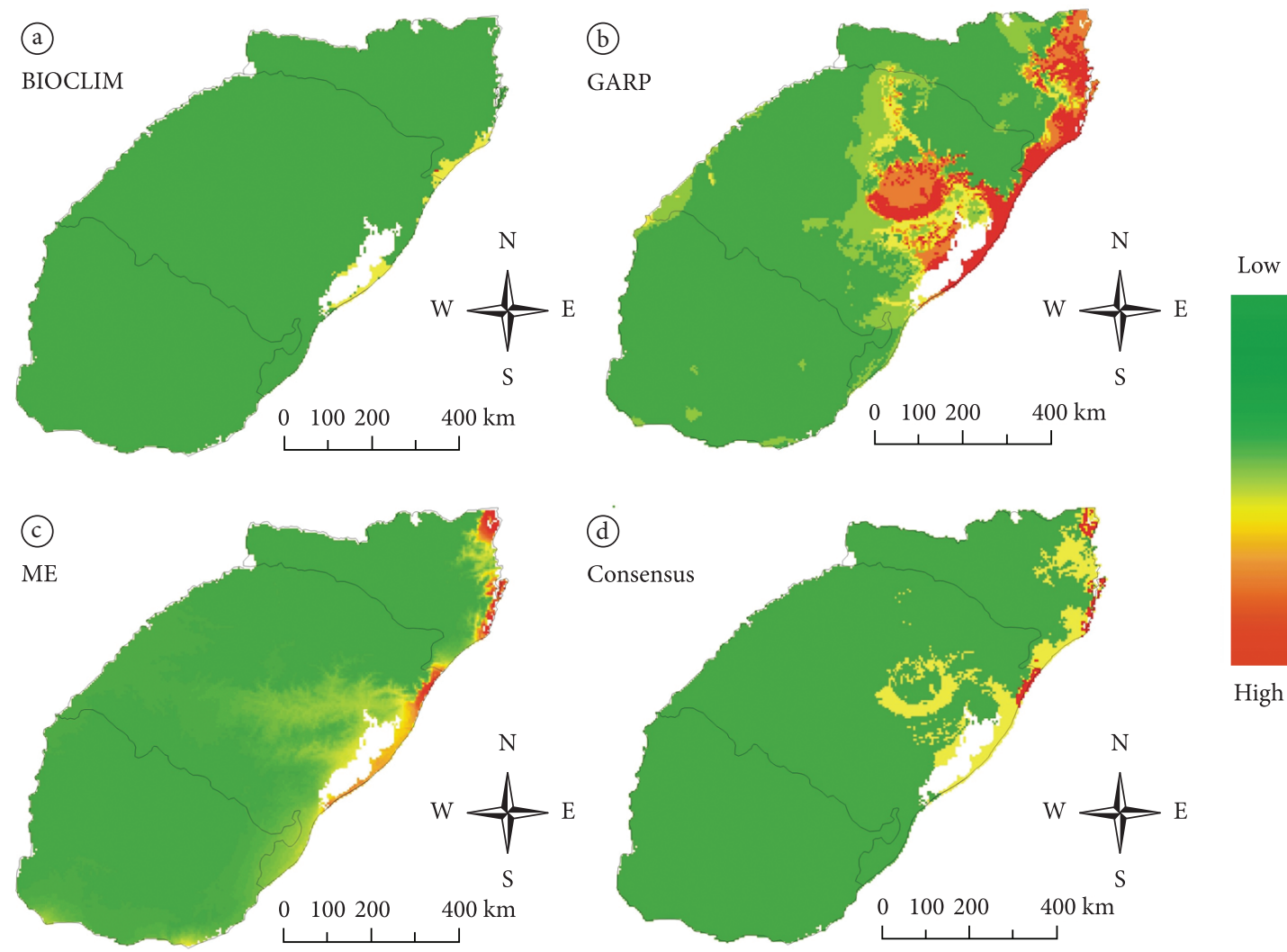

Figure 2. Suitable areas for Melanophryniscus dorsalis according to: a) BIOCLIM, b) GARP, c) ME and d) Consensus Model.
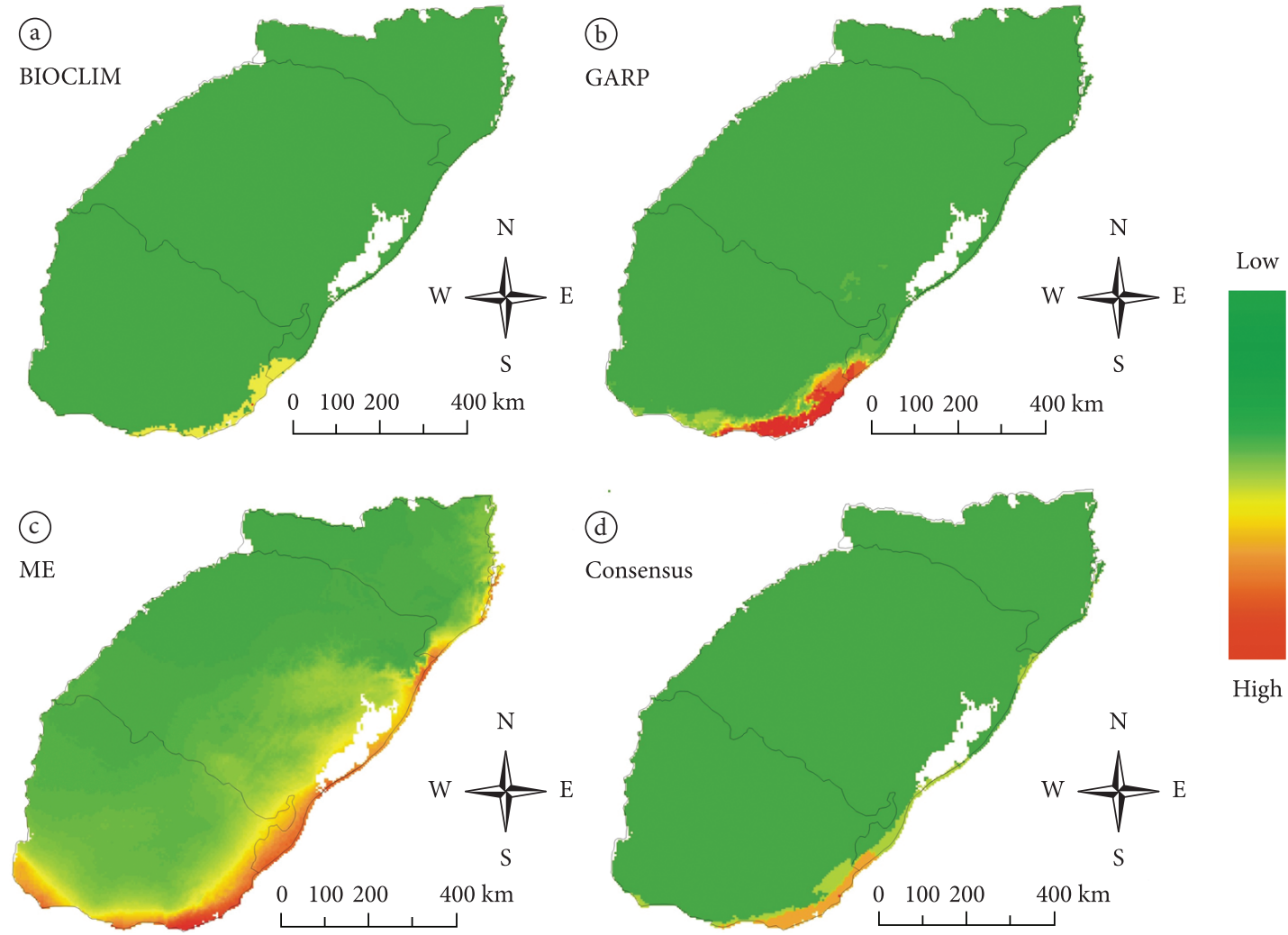

Figure 3. Suitable areas for Melanophryniscus montevidensis according to: a) BIOCLIM, b) GARP, c) ME and d) Consensus Model. 


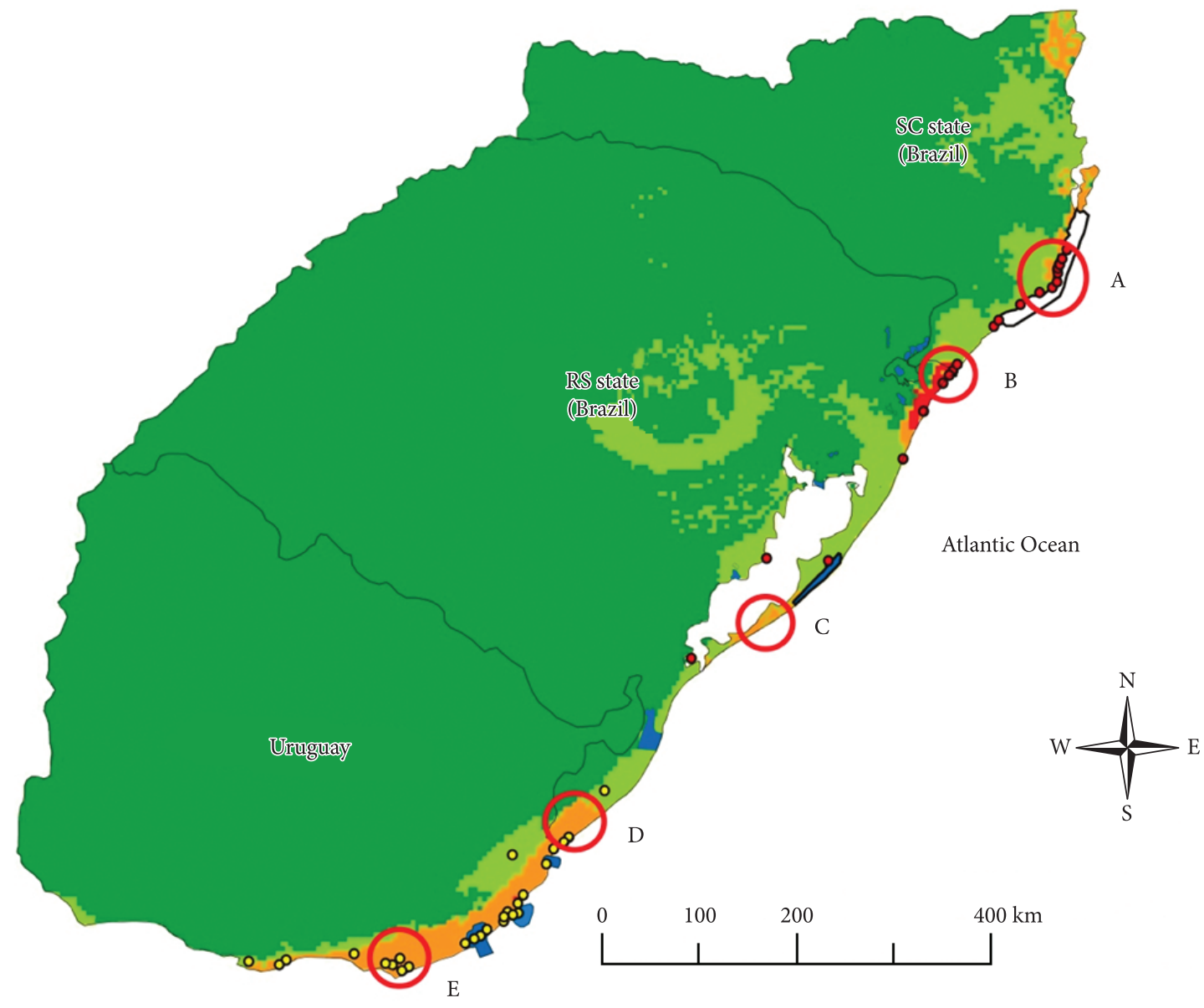

Figure 4. Proposed areas for creation or activation of Conservation Units to preserve the red-bellied toads Melanophryniscus dorsalis and M. montevidensis.

\section{Discussion}

\section{New occurrence data}

Ecological aspects of both species related to explosive reproductive behavior (Maneyro \& Kwet 2008; Haddad 2008; Kwet et al. 2005) did not allow us to confirm absence when individuals were not found in environmentally suitable locations during the fieldwork. We searched actively for specimens of $M$. dorsalis at the southern end of its distribution on the "Ilha dos Marinheiros" in Rio Grande. We made four field expeditions during the known reproductive explosion conditions (after intensive rains in suitable areas), and found specimens only during the fourth expedition, with no reproductive behavior recorded. This may indicate that specific aspects of its activity should be observed at other potential sites of occurrence and reproduction. Points 6 and 8 (Table S1) are not only new species records, but also significantly extend the former restricted distribution by 200 kilometers. Point 6 is the first record of M. dorsalis outside the ocean-beach environment, on the west side of the Lagoa dos Patos, confirmed by this study. Occurrence records 19, 20 and 25 for $M$. montevidensis updated the registry of the Red Book of Endangered Fauna of Brazil (Haddad 2008) and the Red List of Threatened Species of Rio Grande do Sul (Garcia \& Vinciprova 2003). However, these records were, surprisingly, never included in the red data books. These localities were probably excluded from previous publications because of identification errors and/or because they were based only on published records. Maneyro \& Kwet (2008) have recommended the inclusion of M. montevidensis in the list of endangered species for Rio Grande do Sul, because of its restricted occurrence in Brazil.

\section{Consensus models and areas for conservation}

The final consensus models based on all available data for the two species showed important commission errors, such as the areas of high environmental suitability on Florianópolis Island (Santa Catarina), where neither species was recorded (Figure 4). These most likely occur due to an inherent characteristic of the modeling process using ENMs, which does not consider the presence of natural barriers to occupation and other factors, such as effects of biotic interactions, so models only predict 
environmentally appropriate sites (even so assuming that the correct environmental drivers of distributions were included in the modeling process). However, it is also possible to argue the absence of some species in highly suitable areas may indicate recent extinctions. For example, M. montevidensis was recorded previously in Canelones Department, Uruguay, which shows high environmental suitability, but where it is now considered extinct there (Maneyro \& Langone 2001).

The alpha-diversity evaluation used to generate the hotspot map allowed us to demonstrate conservative niche characteristics for a terminal phylogenetic branch, indicating recent environmental history requirements common to both species. When applied to phylogenetically terminal species with conservative niche characteristics, this function allows one to qualitatively identify which environments are most suitable for both species.

Based on the hotspot map, we suggested five important areas for species conservation (Figure 4). These areas shelter a significant number of threatened species, such as the mammals Ctenomys flamarioni and C. minutus, and the lizard Liolaemus occipitalis (IUCN 2011). We found the highest probability for alpha diversity in these areas. In Santa Catarina, the "Baleia Franca" Environmental Protection Area ("Baleia Franca" APA) contains the site with the greatest potential for $M$. dorsalis conservation (area A in Figure 4). Some locations in this region harbor endangered species and also meet the technical requirements for the establishment of protected areas in Brazil, i.e., the presence of rare or endangered species, ecosystems and processes.

Another area on the southern edge of the Baleia Franca APA, covering known populations of $M$. dorsalis, is the Morro dos Conventos in Araranguá Municipality. In addition to meeting the above requirements, this area also attracts tourists because of its coastal rock formations and scenic beauty, increasing the potential for the creation of a protected area. However, the purpose of the Baleia Franca APA is marine environmental conservation, and it is ineffective in protecting threatened continental species. Thus, we suggest the creation of a new conservation unit at hotspot $A$ to ensure the preservation of $M$. dorsalis (Figure 4).

At hotspot $B$ (Figure 4 ) we found two protected areas, Itapeva and Guarita state parks, which are neighboring areas located in northeastern Rio Grande do Sul. The larger Itapeva Park protects a remnant of Atlantic Forest, and is categorized as an Integral Protection Area to protect ecosystems and rare or threatened species (Rio Grande do Sul 2006). The latest Itapeva Park management plan was completed in October 2010, and the study still needs to be approved by the State Secretariat of the Environment. This approval will legally establish Itapeva Park as an actual protected area. Political problems have historically been an obstacle to the establishment of protected areas, depending on Brazilian governmental actions to be executed. Several technical studies have demonstrated the importance of this site in protecting a unique ecosystem in southern Brazil (Wacchter 1986; Colombo et al. 2008). Our study reinforces the effectiveness of the park as an important conservation area for M. dorsalis.

Toward the south, two other areas were represented in our analysis, $C$ and $D$. Site $C$ not only has the most suitable environmental characteristics for these amphibians, but also connects the northern boundary of the distribution of $M$. dorsalis. Site $D$ is the only known record of M. montevidensis in Brazil. The region has also the only record of another threatened Brazilian amphibian, Ceratophrys ornata (Vinciprova \& Garcia, 2003), which occurs along the narrow coastal strip between Rio Grande and Santa Vitória do Palmar municipalities.

Although today some protected areas do shelter M. montevidensis populations in Uruguay, these areas are located in the northern part of the species' distribution and do not include the recorded southern localities. In Montevideo and Canelones Departments, the species is now considered extinct, with no recent records (Maneyro \& Langone 2001). However, in the Department of Maldonado there are still current records, but no conservation actions or protected areas have been implemented. Thus, creating a protected area in this region is extremely important for the preservation of M. montevidensis (area E in Figure 4).

Despite the indication of highly suitable areas in northeastern Santa Catarina, we found no specimens of $M$. dorsalis on the north edge of Imbituba Municipality. By considering the absence of historical records of $M$. dorsalis north of Imbituba Municipality, it is unlikely that this species now occurs in these suitable areas.

Although the identification of highly suitable areas for both taxa provides important information for their conservation, the size and genetic status of their populations still need to be evaluated. Our results and conclusions can provide helpful information to the Brazilian government, through the National Action Plan $(P A N)$ for the conservation of threatened amphibians and reptiles of southern Brazil managed by the Chico Mendes Institute for Biodiversity Conservation (ICMbio).

\section{Acknowledgements}

The authors thank the Fundação O Boticário de Proteção a Natureza (Process No. 0812_20091) for financial support. Our thanks also to the Chico Mendes Institute for Biodiversity Conservation (ICMBio) for logistical support and for a permit (numbers 15556-1 and 15556-2) to collect specimens. To Bianca Zimmermann, Federico and Karin Achaval-Copes, Fernando Quintela, Gustavo Canella, Ivan Amaral, Luiz Ugioni, Mariana Beheregaray, Paula Rorato and Patrícia Langone for field assistance. Drs. Fabiana Barbosa, Maria Rodriguez and Rodrigo Fornel made valuable critiques and suggestions in early draft. Jorge Bernardo-Silva received a doctoral scholarship from CAPES, C. Martins-Ferreira 
is a REUNI CAPES postdoctoral fellow, and T. O. de Freitas has financial support from CNPq 307018/2009-1. RM has financial support from the Agencia Nacional de Investigación e Innovación (ANII - Uruguay) from the project FCE 2514. We want to thank the reviewers LC Terribile, R Dobrovolski and Editor JAF Diniz- Filho for valuable suggestions made on earlier drafts.

\section{References}

Araújo MB \& New M, 2007. Ensemble forecasting of species distributions. Trends in Ecology and Evolution, 22:42-27. PMid:17011070. http://dx.doi.org/10.1016/j.tree.2006.09.010

Colombo $\mathrm{P}$ et al., 2008. Composição e ameaças à conservação dos anfíbios anuros do Parque Estadual de Itapeva, município de Torres, Rio Grande do Sul, Brasil. Biota Neotropica, 8(3):229-240. http://dx.doi.org/10.1590/ S1676-06032008000300020

Crawford AJ et al., 2010. Epidemic disease decimates amphibian abundance, species diversity, and evolutionary history in the highlands of central Panama. Proceedings of the National Academy of Sciences of the U.S.A., 31-107:13777-13782. http://dx.doi.org/10.1073/pnas.0914115107

De Siqueira MF et al., 2009. Something from nothing: Using landscape similarity and ecological niche modeling to find rare plant species. Journal for Nature Conservation, 17:25-32. http://dx.doi.org/10.1016/j.jnc.2008.11.001

Franklin J, 2009. Mapping Species Distributions. Cambridge: Cambridge University Press.

Garcia PCA \& Vinciprova G. 2003. Anfíbios. In: Fontana et al., (eds.). Livro Vermelho da Fauna Ameaçada de Extinção no Rio Grande do Sul. Porto Alegre: EDIPUCRS. p. 85-100.

Giovanelli JGR et al., 2008. Modelagem do nicho ecológico de Phyllomedusa ayeaye (Anura: Hylidae): previsão de novas áreas de ocorrência para uma espécie rara. Neotropical Biology and Conservation, 3(2):59-65.

Haddad CFB, 2008. Uma análise da lista brasileira de anfíbios ameaçados de extinção. In: Machado ABM et al., (eds.). Livro Vermelho da Fauna Brasileira Ameaçada de Extinção. Brasília, Belo Horizonte: Fundação Biodiversitas. v. 2, p. 286-325.

Hesp PA et al., 2009. The Holocene Barrier Systems of the Santa Catarina Coast, Southern Brazil. In: Dillenburg SR \& Hesp PA (eds.). Geology and Geomorphology of Holocene Coastal Barriers of Brazil. Berlin: Springer. p. 92-133. http://dx.doi. org/10.1007/978-3-540-44771-9_4

Hijmans RJ et al., 2005. Very high resolution interpolated climate surfaces for global land areas. International Journal of Climatology, 25:1965-1978. http://dx.doi.org/10.1002/ joc. 1276

International Union for Conservation of Nature - IUCN, 2011. IUCN Red List of Threatened Species. version 2011.2. Available from: <www.iucnredlist.org>. Access in: Mar. 2012.

Kwet A et al., 2005. Advertisement calls of Melanophryniscus dorsalis (Mertens, 1933) and M. montevidensis (Philippi, 1902), two parapatric species from southern Brazil and Uruguay, with comments on morphological variation in the Melanophryniscus stelzneri group (Anura: Bufonidae). Salamandra, 41(1-2):1-18.

Maneyro R \& Kwet A, 2008. Amphibians in the border region between Uruguay and Brazil: Updated species list with comments on taxonomy and natural history (Part I: Bufonidae). Stuttgarter Beiträge zur Naturkunde A, 1:95-121.

Maneyro R \& Langone JA, 2001. Categorización de los anfibios del Uruguay. Cuadernos de Herpetología, 15(2):107-118.

Muñoz MES et al., 2011. openModeller: a generic approach to species' potential distribution modelling. Geoinformatica, 15:111-135. http://dx.doi.org/10.1007/ s10707-009-0090-7

Núñez D et al., 2004. Distribución geográfica de la fauna de anfibios del Uruguay. Smithsonian herpetological Information Series, 134:1-34.

Phillips SJ et al., 2006. Maximum entropy modeling of species geographic distributions. Ecological Modelling, 190:231-259. http://dx.doi.org/10.1016/j.ecolmodel.2005.03.026

Quintela FM et al., 2007. Amphibia, Anura, Bufonidae, Melanophryniscus dorsalis: Distribution extension in the State of Rio Grande do Sul, Brazil. Check List, 2(3):100-103

Rio Grande do Sul. Secretaria Estadual do Meio Ambiente - SEMA, 2006. Plano de Manejo do Parque Estadual de Itapeva. Porto Alegre: SEMA. p. 274.

Rodríguez JP et al., 2007. The application of predictive modelling of species distribution to biodiversity conservation. Diversity and Distributions, 13:243-251. http://dx.doi. org/10.1111/j.1472-4642.2007.00356.x

Rodríguez-Soto C et al., 2011. Predicting potential distribution of the jaguar (Panthera onca) in Mexico: Identification of priority areas for conservation. Diversity and Distributions, 17:350-361. http://dx.doi. org/10.1111/j.1472-4642.2010.00740.x

Stuart SN et al., 2004. Status and trends of amphibian declines and extinctions worldwide. Science, 306:1783-1786. PMid:15486254. http://dx.doi.org/10.1126/science.1103538

Wacchter JL, 1986. Epífitos vasculares da mata paludosa do Faxinal, Torres, Rio Grande do Sul, Brasil. Iheringia, 34: 39-49.

Received: October 2012

First Decision: November 2012 Accepted: November 2012 